\title{
Spontaneous recovery after extinction of a conditioned taste aversion
}

\author{
JUAN M. ROSAS and MARK E. BOUTON \\ University of Vermont, Burlington, Vermont
}

\begin{abstract}
Four experiments examined whether or not spontaneous recovery could occur after extinction in the conditioned taste-aversion paradigm. After three extinction trials, spontaneous recovery was obtained over an 18-day retention interval (Experiments 1,2, and 3). The effect was not due to changes in the unconditioned preference for saccharin over the retention interval (Experiment 2) or to an increase in a nonextinguished aversion over time, as indicated by tests with both the original, nonextinguished aversion (Experiment 1) and with a weaker one (Experiment 3). Spontaneous recovery was not obtained when extinction was overtrained (eight trials) and a 49-day retention interval was used (Experiment 4). However, saccharin intake at asymptote reached the level of baseline water intake, and not the highly preferred level shown by never-conditioned controls. Results of all four experiments suggest that extinction does not return an averted taste to the status of an unconditioned one.
\end{abstract}

Nonreinforced exposure to a conditioned stimulus (CS) that has been previously paired with an unconditioned stimulus (US) yields a progressive decrease in the conditioned response (CR) that is known as extinction. Spontaneous recovery is the increase in the CR that is usually found when the CS is presented again in a test conducted after a retention interval. This well-known phenomenon was discovered by Pavlov (1927) at the beginning of the century, and is one of the main phenomena used to argue against the possibility that extinction causes unlearning of the original CS-US association.

The present article is concerned with taste-aversion learning, in which a flavor is associated with illness. The resulting flavor aversion can be extinguished if the flavor is then repeatedly presented alone. However, to the best of our knowledge, no published work has reported spontaneous recovery of an aversion after extinction. A near exception is an experiment conducted by Kraemer and Spear (1992). These authors found spontaneous recovery when the extinguished flavor was different from the flavor that was conditioned and tested. However, when the same flavor was used in conditioning, extinction, and testing, no recovery was observed. Thus, spontaneous recovery was found after generalized extinction but not after ordinary extinction. Kraemer and Spear reported analogous results in latent inhibition. That is, generalized latent inhibition was lost after a rentention interval, whereas ordinary latent inhibition (where preexposure,

This research was supported by a grant from the Basque Government's Programa de Formación de Investigadores (Ref. BFI94.140) to J.M.R. and by U.S. National Science Foundation Grant IBN9209454 to M.E.B. Address correspondence to J. M. Rosas or M. E. Bouton, Department of Psychology, The University of Vermont, Burlington, VT 05405-0134. conditioning, and testing were conducted with the same flavor) was not. More recently, Aguado, Symonds, and Hall (1994) found an attenuation of latent inhibition after a retention interval using the same flavor (saccharin) in every phase of the experiment. If latent inhibition and extinction share a common explanation (see also Bouton, 1991, 1993), it seems reasonable to suppose that spontaneous recovery in taste aversion might also be possible under some conditions using the same flavor through the whole experiment. However, this has yet to be shown.

Several postextinction effects that argue against an unlearning account of extinction appear to have been difficult to obtain in taste-aversion learning. First, it has already been mentioned that at least one explicit test of spontaneous recovery found none (Kraemer \& Spear, 1992). Second, some experiments have found that reacquisition after extinction in taste-aversion learning proceeds exceedingly slowly (e.g., Danguir \& Nicolaidis, 1977; Hart, Bourne, \& Schachtman, 1995). Third, early experiments in our laboratory did not find any evidence of reinstatement of the conditioned taste aversion after one or several exposures to the US after extinction (Bouton, 1982). Reinstatement has been obtained in subsequent taste-aversion experiments (Schachtman, Brown, \& Miller, 1985), but some of the evidence of it has been surprisingly indirect. For instance, Schachtman, Gustavson, Chelonis, and Bourne (1992; see also Gustavson, Hart, Calton, \& Schachtman, 1992) found no actual recovery of the aversion to the extinguished taste. Instead, they reported a restoration of its ability to block (e.g., Kamin, 1969) an aversion conditioned to a new taste that was conditioned in serial compound with it. In some of the experiments, the blocking effect was actually confounded with a US preexposure effect. Finally, Archer and his colleagues (e.g., Archer \& Sjödén, 1981; Archer, Sjödén, \& Nilsson, 1985; Archer, Sjödén, Nilsson, \& Carter, 
1979, 1980; Sjödén \& Archer, 1989) have found that a taste aversion was partially restored when the flavor was returned to the original conditioning context after extinction in another context. This effect resembles the "renewal effect" found in other conditioning preparations (e.g., Bouton \& Bolles, 1979; Bouton \& King, 1983; Bouton \& Peck, 1989). However, the taste-aversion experiments usually found a loss of the conditioned response when the context was switched after conditioning (e.g., Archer et al.,1980; Sjödén \& Archer, 1989). In experiments reporting renewal in fear conditioning (e.g., Bouton \& King, 1983) and in appetitive conditioning (e.g., Bouton \& Peck, 1989), no loss of responding was found. The loss in taste-aversion learning leaves open the possibility that the flavor was perceived as different in the two contexts, therefore suggesting that the original flavor was never extinguished. Even in the rare experiments where the aversion was not reduced with the contextual change (Archer \& Sjödén, 1981), differences in the familiarity of the contexts permit alternative explanations of the effect. While these remain open, the renewal of taste aversion found by these authors is not a strong argument against the unlearning hypothesis. Indeed, the evidence against this hypothesis in CTA seems sufficiently mixed to leave room for the claim that taste aversion is a special case of learning (e.g., Rozin \& Kalat, 1971).

Given this background, any empirical evidence concerning the unlearning explanation of extinction in conditioned taste-aversion learning would contribute to our understanding of the phenomenon. The experiments presented in this paper asked whether spontaneous recovery could occur in the taste-aversion paradigm.

\section{EXPERIMENT 1}

In Experiment 1, the effect of a retention interval upon an extinguished taste aversion was compared with that observed after simple excitatory conditioning. The experimental design included four groups. Every rat received one conditioning trial in which a saccharin solution was followed by $\mathrm{LiCl}$-induced illness. Two groups (Ext-S and Ext-L) then received extinction exposure to the saccharin. The strength of the aversion to the saccharin was then tested 1 day (Group Ext-S) or 18 days (Group Ext-L) after the last extinction trial. If spontaneous recovery were to occur with this procedure, the aversion in Group Ext-L should be stronger than that in Group Ext-S. Two control groups (C-L and C-S) were included to test whether the retention interval had a similar effect upon a nonextinguished aversion. Such an "incubation" effect has been reported in the taste-aversion literature (e.g., Batsell \& Best, 1992a, 1994). The control groups did not receive exposure to the saccharin after conditioning, but received the test after a retention interval equivalent to that between conditioning and testing in the two experimental groups.

\section{Method}

Subjects and Apparatus. The subjects were thirty-two 130day-old female Wistar rats purchased from Charles River, Canada.
Twenty-eight had previously served, while food-deprived, in an appetitive conditioning experiment in which tones and/or lights were paired with food pellets in Skinner boxes. The rats received free access to food and water for 12 days before beginning the new experiment; their ad-lib weights ranged between 245 and $312 \mathrm{~g}$ (mean of $270.5 \mathrm{~g}$ ) at the start. They were individually housed with continuous access to food in suspended stainless steel cages $(18 \times$ $20 \times 36 \mathrm{~cm}$ ) in a room maintained on an 18:6-h light:dark cycle. The experiment was conducted in this room on consecutive days during the light portion of the cycle. Fluids were administered at room temperature in $30-\mathrm{ml}$ plastic syringes that had a rubber stopper fitted with a stainless steel drinking spout. The test flavor was a solution of $0.1 \%$ sodium saccharin (sugar substitute), and illness was induced by a $2 \%$ body-weight intraperitoneal injection of $0.15 \mathrm{M} \mathrm{LiCl}$. All fluids were mixed in distilled water.

Procedure. For 5 days, the animals were first subjected to a water-deprivation schedule consisting of two daily 30 -min periods of free access to distilled water. These drinking periods took place at 0900 and $1700 \mathrm{~h}$. The deprivation schedule started on the same day for every subject and was kept unchanged throughout the experiment. In experimental phases, flavored solutions were presented during the first drink period; the animals continued receiving distilled water during the second period throughout the experiment.

On the single conditioning day, all rats received free access to the saccharin solution for $30 \mathrm{~min}$, followed within $15 \mathrm{~min}$ by an injection of $\mathrm{LiCl}$. A recovery day followed in which the animals had access to distilled water for the usual 30-min periods. Groups were then matched on the water consumption during the 5 days of deprivation and on saccharin consumption on the conditioning day. The animals in Groups Ext-L and Ext-S then received free access to saccharin in the morning drink period on each of the next 3 days. The animals in Groups C-L and C-S received water in these periods. After a retention interval, a test was administered in which the animals received three daily sessions of access to saccharin in the morning session.

To ensure that the motivation to drink was equal in the different groups during testing, the test took place on the 29th day of the two-drinks-a-day schedule for all animals. The days on which conditioning (and extinction) occurred were manipulated so that the test occurred 1 day after extinction in Group Ext-S (5 days after the conditioning day in Groups C-S and Ext-S) and 18 days after extinction in Group Ext-L ( 21 days after the conditioning day in Groups C-L and Ext-L).

The amount of liquid consumed was measured to the nearest milliliter and was evaluated by analyses of variance (ANOVA). Planned comparisons were made using the methods discussed by Howell (1987, pp. 431-443). The rejection criterion was set at $p<$ .05 .

\section{Results and Discussion}

Figure 1 shows the saccharin consumption on the conditioning trial, on the 3 days of extinction (for Groups Ext-L and Ext-S), and on the 3 days of testing for all groups. A 2 (retention interval) $\times 2$ (extinction vs. no extinction) ANOVA found no differences in consumption on the conditioning trial $[F \mathrm{~s}(1,28)<1]$. Extinction occurred at the same rate in Groups Ext-L and Ext-S, without remarkable differences between them. A 2 (group) $\times 3$ (trial) ANOVA conducted during the extinction phase found a main effect of trial $[F(2,28)=42.3]$ but not of group $[F(1,14)<1]$ or a group $\times$ trial interaction $[F(2,28)<1]$.

The groups were equally thirsty before the first testing day. The mean water consumption in the afternoon drink 


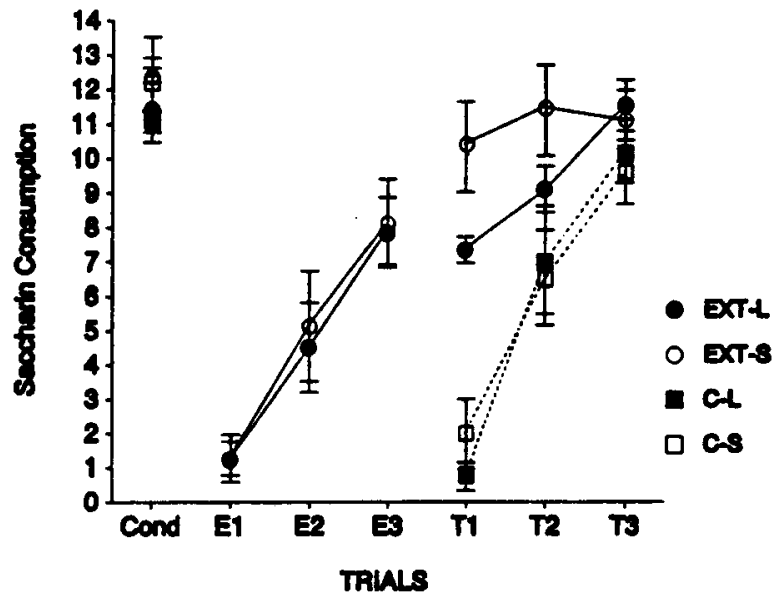

Figure 1. Saccharin consumption on the conditioning trial, on the 3 days of extinction (for Groups Ext-L and Ext-S), and on the 3 days of testing for Groups Ext-L, Ext-S, C-L, and C-S in Experiment 1.

the day before the test was $5,6.12,5.25$, and $5.63 \mathrm{ml}$ for Groups Ext-L, Ext-S, C-L, and C-S, respectively. A 2 (extinction) $\times 2$ (retention interval) ANOVA found no differences in consumption $[F \mathrm{~s}(1,28) \leq 2.24]$.

At the beginning of the test, the mean saccharin intake was lower in Group Ext-L than in Group Ext-S; the intake in the control groups was even lower. These differences became smaller as extinction progressed during the test. A 2 (retention interval) $\times 2$ (extinction) $\times 3$ (trial) ANOVA found main effects of extinction $[F(1,28)=$ $21.5]$ and trial $[F(2,56)=62.4]$ but not of the retention interval $[F(1,28)<1]$. The retention interval $\times$ trial $[F(2,56)=3.5]$ and extinction $\times$ trial $[F(2,56)=19.6]$ interactions were also significant. Neither the retention interval $\times$ extinction $[F(1,28)<1]$ nor the retention interval $\times$ extinction $\times$ trial interaction $[F(2,56)<1]$ were significant. The retention interval $\times$ trial interaction was due to the fact that the retention-interval effect was significant on the first test trial $[F(1,51)=4.1]$ but not on the others $(F \mathrm{~s}<1)$. Subsequent analyses that explored the extinction $\times$ trial interaction found that less saccharin was consumed by the control subjects than by the extinguished subjects in the first and second test trials $[F(1,51) \geq 11.2]$ but not in the third $[F(1,51)=1.7]$. However, when the extinguished groups were isolated, the increase was reliable only in Group Ext-L. A 2 (retention interval) $\times 3$ (trial) ANOVA conducted with the extinguished groups (Ext-L and Ext-S) found a main effect of trial $[F(2,28)=9.1]$ but not of retention interval $[F(1,14)=1.8]$. Most important, the retention interval $\times$ trial interaction was significant $[F(2,28)=4.8]$. Subsequent analyses showed a lower consumption after the long retention interval (Group Ext-L) than after the short one (Group Ext-S) on the first test trial $[F(1,22)=4.7]$. An identical analysis run with the control groups found a main effect only of trial $[F(2,28)=56.98]$, but neither the group effect nor the group $\times$ trial interaction was significant $(F \mathrm{~s}<1)$.
These results suggest that the long retention interval reduced saccharin consumption after extinction but not after conditioning alone. This lower consumption can be interpreted as spontaneous recovery of the extinguished aversion. It is significant that there was no evidence that the retention interval had any effect on the aversion conditioned and tested without extinction (cf. Batsell \& Best, 1992a, 1994). However, it is possible that the decrease in extinguished saccharin consumption after the long retention interval could be a consequence of a change in saccharin preference that was masked by a floor effect present at the start of testing in the present control groups. This was further examined in Experiments 2 and 3 .

\section{EXPERIMENT 2}

The design of the second experiment was similar to that of the first, except that the two control groups now received unpaired exposure to the saccharin and $\mathrm{LiCl}$. In addition, overall exposure to the saccharin was equated in all groups. The design allowed us to replicate the spontaneous recovery effect observed in Experiment 1 and also to assess whether the retention interval caused any change in the rats' unconditioned saccharin intake.

\section{Method}

Subjects and Apparatus. The subjects were 33 female Wistar rats from the same stock as before, which had likewise been used in an experiment on appetitive conditioning. The rats received 14 days of free access to water and food before the new experiment was begun. They were about 115 days old at the start and ranged in ad-lib weight from 208 to $287 \mathrm{~g}$ (a mean of $251.3 \mathrm{~g}$ ). Maintenance conditions and apparatus were the same as those in Experiment 1.

Procedure. The procedure was identical to the one used in Experiment 1 except as noted. The groups were matched on water consumption during the 5 initial deprivation days preceding the conditioning session. During the conditioning day, all rats received access to the saccharin solution for $30 \mathrm{~min}$. The animals in Groups Ext-L and Ext-S received an injection of $\mathrm{LiCl}$ within $15 \mathrm{~min}$. The animals in Groups UP-S and UP-L received the same injection after consuming distilled water during their morning drink the next day. A recovery day followed in which all animals had access to water for the usual 30-min periods. Beginning the next day and continuing for the following 2 days, all rats received access to saccharin in the morning drink period. Two days of testing, in which the saccharin solution was presented in the $30-\mathrm{min}$ morning session, were administered after a 1-day (Groups Ext-S and UP-S) or an 18-day (Groups Ext-L and UP-L) retention interval. As before, the test took place on the same day (the 30th day of the two-drinks-a-day schedule) in every group.

\section{Results and Discussion}

Two rats (one in Group Ext-L and the other in Group Ext-S) were discarded because they failed to drink any saccharin during extinction (the same criterion was applied in every experiment).

Figure 2 shows the saccharin consumption on the conditioning trial, the 3 days of exposure in extinction, and the 2 days of testing in all four groups. A 2 (retention interval) $\times 2$ (pairing) ANOVA on consumption during the 


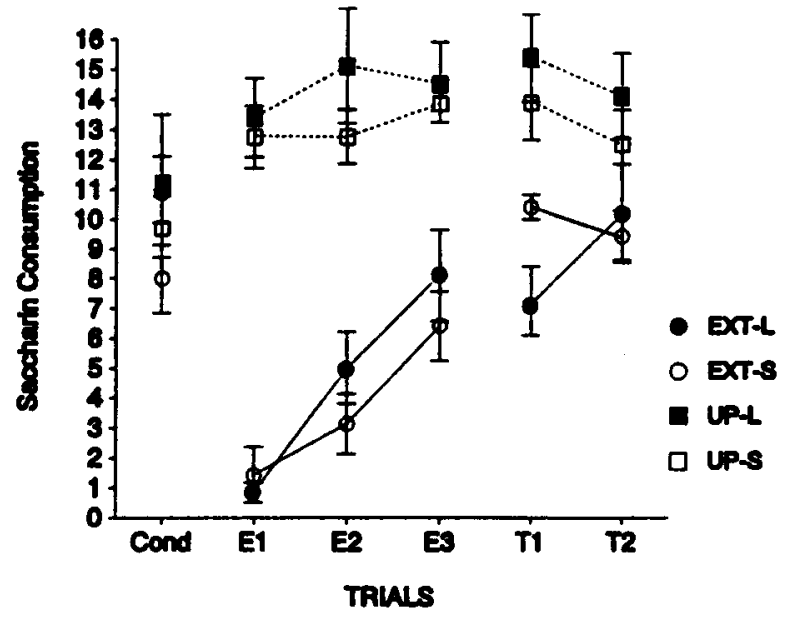

Figure 2. Saccharin consumption on the conditioning trial, the 3 days of exposure to the saccharin in extinction, and on the 2 days of testing for Groups Ext-L, Ext-S, UP-L, and UP-S in Experiment 2.

conditioning trial did not find any main effect or interaction $[F \mathrm{~s}(1,27) \leq 3.89]$. As in the first experiment, extinction proceeded uneventfully. The subjects that had received the saccharin paired with the $\mathrm{LiCl}$ increased their consumption over trials, but it remained below the consumption of the unpaired groups, which did not change over trials. A 2 (retention interval) $\times 2$ (pairing) $\times 3$ (trial) ANOVA conducted on the extinction data found a main effect of pairing $[F(1,27)=93.7]$ and trial $[F(2,54)=28.6]$ but not of the retention interval $[F(1,27)=1.6]$. The pairing $\times$ trial interaction was significant $[F(2,54)=13.1]$, but none of the interactions involving the retention interval were $(F \mathrm{~s} \leq 2.3)$. Subsequent analyses run to explore the pairing $X$ trial interaction found a simple effect of trial in the paired groups undergoing extinction $[F(2,54)=39.97]$ but not in the unpaired groups $[F(2,54)=1.7]$. Otherwise, the simple effect of pairing was significant on every trial $\left[F_{\mathrm{S}}(1,46) \geq\right.$ 34.5]. Thus, the groups' intakes had not converged on the same point by the last extinction trial.

The mean water consumption in the afternoon session the day before testing began was $6.63,7.14,5.63$, and $5.25 \mathrm{ml}$ in Groups Ext-L, Ext-S, UP-L, and UP-S, respectively. A 2 (retention interval) $\times 2$ (pairing) ANOVA did not find any differences in consumption $[F(1,27) \leq$ 3.81], suggesting that the groups did not differ in their deprivation before the test.

Of main interest are the results of testing. The results in the two extinction groups replicated the previous experiment; there was less consumption after the long than after the short retention interval. In contrast, there was no effect of retention interval in the two unpaired groups. A 2 (retention interval) $\times 2$ (pairing) $\times 2$ (trial) ANOVA conducted on the test consumption found a main effect of pairing $[F(1,27)=15.7]$ but not of retention interval or trial $\left(F_{\mathrm{s}}<1\right)$. The retention interval $\times$ trial and the pairing $\times$ trial interactions were significant $[F \mathrm{~s}(1,27) \geq$
5.9], but the retention interval $\times$ pairing interaction was $\operatorname{not}[F(1,27)=1.4]$. The three-way interaction was also significant $[F(1,27)=5.2]$. Subsequent analyses exploring this interaction found that the retention interval $X$ trial interaction was significant only in the Ext groups $[F(1,27)=10.7]$ but not in the UP groups $(F<1)$. The interaction was due to the fact that Groups Ext-S and Ext-L differed reliably on the first test trial $[F(1,27)=$ 24.9] but not on the second $(F<1)$. Furthermore, there was a simple effect of trial in Group Ext-L $[F(1,27)=$ $12.8]$ but not in Group Ext-S $[F(1,27)=1.25]$. No differences were found between Groups UP-S and UP-L on either test trial $(F \mathbf{S}<1)$.

The results of this experiment replicated those obtained in Experiment 1: There was less saccharin consumption when the test was conducted 18 days after extinction than when it was conducted only 1 day after extinction. As in Experiment 1, this was a transient effect, disappearing after the first test trial. Most important, however, is the fact that there were no changes in saccharin consumption over the retention interval when saccharin had not been paired with illness. The decrease in the saccharin consumption observed after extinction thus appears to depend on initial aversion conditioning.

The results thus strongly suggest that spontaneous recovery of a conditioned taste aversion can be obtained. However, in Experiments 1 and 2, testing might have been conducted before extinction was complete. On the one hand, saccharin consumption did not increase significantly during testing when the retention interval was short (Experiments 1 and 2), suggesting that extinction was at asymptote by the first trial of testing. On the other hand, the extinguished rats did not reach the level of consumption shown by the unpaired subjects. Thus, it could be argued that at the end of the extinction phase there was still a weak conditioned taste aversion. This point is relevant, because the memory of incompletely learned, nonasymptotic associations can improve with the retention interval (e.g., Gisquet-Verrier \& Alexinsky, 1988). Indeed, in conditioned taste-aversion learning, a relatively weak aversion does increase over time (e.g., Batsell \& Best, 1992a, 1992b, 1994). It is worth noting that the increase in aversion found by Batsell and Best reached a maximal level about $48 \mathrm{~h}$ after conditioning, well before testing after our shortest retention interval occurred ( 5 or 6 days after conditioning). Even though this suggests no direct reason to expect incubation between the intervals tested here, it is possible that, with our particular parameters, the strength of weak aversion might still increase with the longer retention interval. We found no such increase in Experiment 1, but it could have been hidden by a floor effect that was evident at the onset of testing in that experiment.

\section{EXPERIMENT 3}

Experiment 3 was conducted to determine whether a weak taste aversion was influenced by the retention interval that increased the aversion to our extinguished fla- 
vor. As in Experiment 1, we again compared the effect of the retention interval after extinction and simple conditioning. However, here the control rats received conditioning with a smaller US, specifically, an injection that was one fourth the size of our usual dose of $\mathrm{LiCl}$. A pilot experiment had shown that this dose $(0.15 \mathrm{M} \mathrm{LiCl}$ at $0.5 \%$, rather than $2 \%$, body weight) leads to an intermediate level of conditioning that would leave space on the consumption scale to detect either an increase or decrease in the aversion after the retention interval. In fact, the dose was expected to produce an aversion roughly comparable to that observed at the end of extinction in the extinguished groups. Thus, the experiment was designed to ask whether the effect of retention interval on a weak aversion depended on the conditioning history or path (extinction or simple conditioning) taken to arrive at it.

\section{Method}

The subjects were 32 female Wistar rats from the same stock as before, which had, once again, been used in an experiment on appetitive conditioning. They received free access to food and water for 15 days before the present experiment was begun. The rats were about 140 days old and ranged in ad-lib weight from 228 to $300 \mathrm{~g}$ (a mean of $275 \mathrm{~g}$ ) at the start. Maintenance conditions and apparatus were the same as in the previous experiments. The procedure was exactly the same as that in Experiment 1, except that illness in the two control groups $(0.5 \%-\mathrm{L}$ and $0.5 \%-\mathrm{S})$ was induced by a $0.5 \%$ body-weight intraperitoneal injection of $0.15 \mathrm{M}$ $\mathrm{LiCl}$. The treatment of Groups Ext-L and Ext-S was the same as that in Experiment 1.

\section{Results and Discussion}

Figure 3 shows the saccharin consumption in the conditioning trial, the 3 days of extinction, and the 2 days of testing. A 2 (retention interval) $\times 2$ (dose level) ANOVA on consumption on the conditioning day did not find any significant main effects or interaction $[F \mathrm{~s}(1,28) \leq 3.18]$. During extinction, a 2 (retention interval) $\times 3$ (trial) ANOVA comparing the two extinguished groups found a main effect of trial $[F(2,28)=44.37]$, but neither a

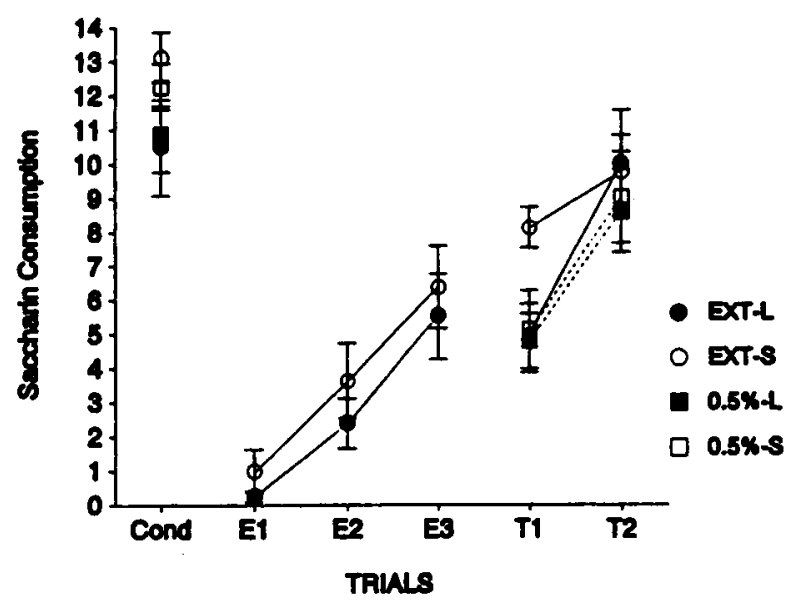

Figure 3. Saccharin consumption on the conditioning trial, the 3 days of extinction, and over the 2 days of testing in Groups Ext-L, Ext-S, 0.5\%-L, and 0.5\%-S in Experiment 3 . main effect of retention interval nor a retention interval $\times$ trial interaction $(F \mathrm{~s}<1)$.

The mean water consumption in the afternoon session before the first test day was $6.87,5.87,5.25$, and $5 \mathrm{ml}$ for Groups Ext-L, Ext-S, 0.5\%-L, and 0.5\%-S, respectively. A 2 (retention interval) $\times 2$ (extinction) ANOVA found no differences in water consumption $[F \mathrm{~s}(1,28) \leq 2.37]$. As usual, the groups did not differ in their motivation to drink prior to testing.

With respect to the main concern of this experiment, the extinguished saccharin consumption was again suppressed after the long retention interval, replicating the results of the previous experiments. Moreover, there was no effect of the retention interval on the weak aversion in the two control groups. A 2 (retention interval) $\times 2$ (extinction) $\times 2$ (trial) ANOVA on test consumption found a significant main effect of trial $[F(1,28)=99.4]$ and significant retention interval $\times$ trial and retention interval $\times$ extinction $\times$ trial interactions $[F \mathrm{~s}(1,28) \geq 5.79]$. The other effects or interactions were not significant $[F \mathrm{~s}(1,28) \leq 1.54]$. Analyses run to explore the three-way interaction found that the retention interval $\times$ trial interaction was significant in the subjects that had received previous extinction $[F(1,28)=11.5]$ but not in those that had not $(F<1)$. Saccharin consumption was lower in Group Ext-L than in Group Ext-S on the first test trial $[F(1,35)=4.23]$. The two groups with the weak aversion $(0.5 \%$-L and $0.5 \%$-S $)$ did not differ $(F \mathrm{~s}<1)$. However, Group $0.5 \%-\mathrm{S}$ consumed less saccharin than Group Ext-S $[F(1,28)=5.49]$, showing that the weak aversion was still stronger than the extinguished aversion. Otherwise, the simple effect of trial was significant in every group $[F \mathbf{s}(1,28) \geq 4.98]$.

This experiment again found a recovery of the extinguished saccharin aversion when the test was conducted 18 days after extinction. Most importantly, saccharin consumption did not change over time in the subjects that had only a weak aversion to saccharin. Thus, tasteaversion learning appears to be path dependent, in the sense that the effect of retention interval depends on whether a weak aversion was produced by extinction or by partial conditioning.

\section{EXPERIMENT 4}

In previous experiments, spontaneous recovery was tested after only three extinction trials. It would be useful to know whether spontaneous recovery would also appear after more extensive extinction training, and this was the aim of the final experiment. The design was the same as that used in Experiment 2, except that 8 days of extinction and a 49-day retention interval were used. The choice of retention interval preserved the $6: 1$ ratio between the number of days of the retention interval and extinction that was used in the previous experiments.

\section{Method}

The subjects were 31 female Wistar rats from the same stock as before; they had also been used in an experiment on appetitive 
conditioning. The rats received 10 days of free access to water and food before the new experiment began. They were about 145 days old and ranged in ad-lib weight from 209 to $280 \mathrm{~g}$ (a mean of $248 \mathrm{~g}$ ) at the start of the new experiment. Maintenance conditions and apparatus were the same as before. The design of Experiment 2 , in which we compared paired and unpaired groups, was used. The procedure followed that of Experiment 2 except as noted. Every subject now received 8 days of nonreinforced exposure to saccharin during the extinction phase, and the retention intervals were 49 days for Groups Ext-L and UP-L $(n=7)$ and 2 days for Groups Ext-S and UP-S. Testing occurred on Days 66 and 67 for every subject. The usual water-deprivation schedule started the same day for all animals and was maintained until Day 16 (the 8th day of exposure to the saccharin during the extinction phase in Groups Ext-L and UP-L). All rats then received ad-lib water for the next 31 days. Water deprivation was resumed on Day 48, 5 days before conditioning in Groups Ext-S and UP-S. The procedure arranged things so that, regardless of group assignment, all conditioning and extinction trials were conducted after the same number of local deprivation days. Finally, a water baseline day was given to all the animals the day before the test; Groups Ext-S and Ext-L were thus tested 2 days and 49 days, respectively, following the 8 th extinction trial.

\section{Results and Discussion}

One rat in Group Ext-L failed to show any evidence of extinction and was therefore removed from the experiment. Perhaps not surprisingly, given the lengthy 7-week retention interval, there were systematic differences in baseline water intake in the groups given water during the early conditioning and extinction phases (Days 6-16, Groups Ext-S and UP-S) and the later conditioning and extinction phases (Days 54-64, Groups Ext-L and UP-L). The mean water consumption was 8.81 and $10.01 \mathrm{ml}$ for these animals, respectively. Though small, this difference was also reflected in the saccharin intake observed during the corresponding periods. The mean saccharin consumption during the last four trials of extinction was 8.44 and $10.62 \mathrm{ml}$ for Groups Ext-L (Days 13-16) and Ext-S (Days 61-64), respectively $[F(1,13)=3.79, p=$ .074]. Since this small difference appears to have been an artifact of a general increase in liquid consumption over time, we corrected for it by analyzing saccharin intake data expressed as a proportion of the contemporary baseline water intake. Our use of the proportion measure does not change conclusions based on an analysis of absolute saccharin consumption except where noted.

Figure 4 presents the mean saccharin-water proportion on the conditioning day, the 8 days of exposure to the saccharin in extinction, and the 2 days of testing in all four groups. The proportion was computed for each subject by dividing its saccharin consumption by the mean water intake of the animals that received water in the corresponding session. To compute the proportion on test days, on which all rats received saccharin in the same sessions, saccharin intake was divided by the mean water consumption in the morning session of the water baseline day given immediately before the test (Day 65).

A 2 (retention interval) $\times 2$ (pairing) ANOVA on consumption during the conditioning trial did not find any main effect or interaction $[F \mathrm{~s}(1,26)<1.28]$. During the extinction phase, a 2 (retention interval) $\times 2$ (pairing) $\times$

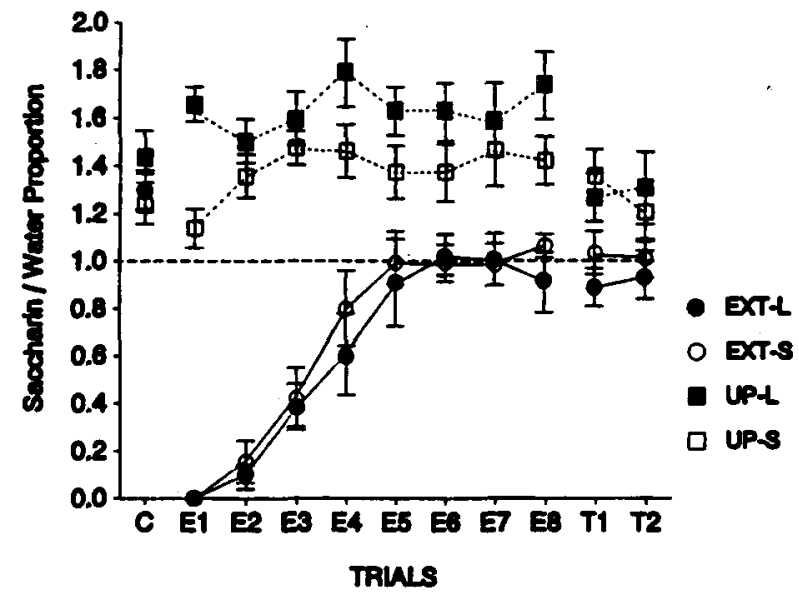

Figure 4. Saccharin-water proportion on the conditioning day, the 8 days of exposure to the saccharin in extinction, and the 2 days of testing in Groups Ext-L, Ext-S, UP-L, and UP-S in Experiment 4.

8 (trial) ANOVA found a significant main effect of pairing $[F(1,26)=99.52]$ and trial $[F(7,182)=44.28]$. The retention interval $\times$ trial, pairing $\times$ trial, and retention interval $\times$ pairing $\times$ trial interactions were also significant $[F \mathrm{~s}(7,182) \geq 2.09]$. Neither the retention interval main effect nor the retention interval $\times$ pairing interaction were significant $\left[F_{\mathrm{s}}(1,26) \leq 2.66\right]$. Exploring the pairing $\times$ trial interaction, we found that the simple effect of pairing was significant on every trial $[F \mathrm{~s}(1,66) \geq$ 21.27]. A 2 (retention interval) $\times 8$ (trial) ANOVA conducted with the two experimental groups (Ext-L and Ext-S) found a main effect of trial $[F(1,66)=30.51]$ but not of retention interval or the interaction $[F \mathrm{~s}(1,66) \leq$ $2.06]$, suggesting a comparable rate of extinction in the two groups. The groups had reached asymptotic extinction by Trial 5. A 2 (retention interval) $\times 4$ (trial) ANOVA conducted in these two groups on Trials 5-8 did not find group, trial, or interaction effects $(F \mathrm{~s}<1)$. The lack of a trial effect indicates that extinction progressed no further after Trial 5 . Note, however, that asymptotic extinction approached a saccharin-water proportion of 1.0. Thus, saccharin was consumed in an amount comparable to water-not nonconditioned saccharin $[F(1,26)=28.67]-$ when asymptote was reached.

A 2 (retention interval) $\times 8$ (trial) ANOVA conducted during extinction with the two control groups found a significant main effect of retention interval $[F(1,66)=13.35]$ but not of trial or a group $\times$ trial interaction $[F(1,66) \leq$ $1.84]$. Group UP-S drank a smaller proportion of saccharin than did Group UP-L. Interestingly, however, the absolute saccharin intake in these groups was equivalent and quite high (means of 14.43 and $13.93 \mathrm{ml}$ for Groups UP-L and UP-S, respectively). The pattern is consistent with the possibility that both groups were drinking as much saccharin as their stomachs could contain. If saccharin consumption in nonconditioned subjects reached the maximum possible, any increase in consumption of 
the less preferred water between the early and later extinction would lead to an artifactual drop in the saccharin-water proportion in Group UP-S. Thus, the difference in proportion was presumably an artifact caused by a ceiling effect in saccharin consumption. This possibility is further consistent with the fact that the difference in proportions disappeared during the test (see below) when the water baseline and saccharin data were taken on the same days, late in the experiment, for both groups.

Turning to the test data, Figure 4 suggests no evidence of spontaneous recovery. This impression was confirmed by statistical analysis. A 2 (retention interval) $\times$ 2 (pairing) $\times 2$ (trial) ANOVA found a significant main effect of pairing $[F(1,26)=13.94]$. Even after eight extinction trials and apparent asymptotic extinction, the extinguished groups still consumed less saccharin than did the controls. None of the other main effects or interactions were significant $\left[F_{\mathrm{s}}(1,26) \leq 1.23\right]$. There were no differences in deprivation level; water consumption in the morning session of the day before testing was 11.1, $11.25,10.71$, and $10.5 \mathrm{ml}$ in Groups Ext-L, Ext-S, UP-L, and UP-S, respectively $[F \mathrm{~s}(1,26) \leq 1.19]$.

This experiment did not find spontaneous recovery after extended extinction training. It is possible, of course, that the retention interval was too short to produce the effect with the present procedure. However, the present retention interval was very long by most standards, and preserved the 6:1 ratio between days in the interval and days in extinction that was used successfully in the previous experiments. In any event, the results suggest that there are boundary conditions for spontaneous recovery in taste-aversion learning (see also Kraemer \& Spear, 1992).

Perhaps the most interesting finding of this experiment was that the saccharin consumption in extinction never reached the level shown by subjects that had never received conditioning. In an important sense, the effects of the original aversion were thus never completely destroyed by extinction. In unpaired animals, the present saccharin concentration was preferred to water (saccharinwater proportion $>1.0$ ). However, extinction did not yield this preference; instead, asymptote was at a point of indifference with water (proportion $=1.0$ ). Extinction evidently returned the saccharin flavor to neutrality, but the rats never acquired a preference for it. An unlearning account of extinction would predict that saccharin consumption would eventually reach the level of consumption in the absence of conditioning. The results therefore continue to suggest that extinction does not destroy the acquired aversive properties of saccharin, even though spontaneous recovery was not evident during the test.

\section{GENERAL DISCUSSION}

Four experiments were conducted to test whether spontaneous recovery could occur after extinction in the conditioned taste-aversion paradigm. Spontaneous recovery was obtained after an 18-day retention interval when three extinction trials were used (Experiments 1,2, and 3). This effect was not due to spontaneous changes in the unconditioned preference for saccharin over the retention interval (Experiment 2). Nor was it due to an increase in the conditioned taste aversion over time after simple conditioning, which we assessed after the conditioning of strong (Experiment 1) and intermediate (Experiment 3 ) taste aversions.

Kraemer and Spear (1992) reported spontaneous recovery from generalized, but not from primary, extinction. The experiments reported here show for the first time that spontaneous recovery from primary extinction can be obtained in taste-aversion learning. The results of these experiments add to the small body of evidence, provided by effects of certain postextinction manipulations, which suggest that the excitatory association is not destroyed during extinction in taste aversion (e.g., Schachtman et al., 1985). In the experiments reported here a special effort was made to rule out any alternative explanations of the decrease in saccharin consumption over the retention interval (see above). Thus, the effect can be safely attributed to spontaneous recovery of the extinguished aversion.

The spontaneous recovery effect found here clearly argues against an unlearning account of taste-aversion extinction. However, it is worth noting that the effect, though consistent and clear, was not numerically large; recovery far from recaptured the strength of the original taste aversion. Moreover, the lack of recovery in Experiment 4 suggests that there are boundary conditions for the effect. Spontaneous recovery was not found in Experiment 4 after extinction training continued for several trials beyond asymptote. It can be argued that Experiment 4's retention interval was not long enough to allow recovery to occur. Although this hypothesis cannot be rejected, the 7-week retention interval was very long by most standards, and its length preserved the ratio of days in the retention interval and days in extinction (6:1) that yielded spontaneous recovery in Experiments 1, 2, and 3. Thus, it seems safe to conclude that overtrained extinction reduces spontaneous recovery, except, perhaps, after extraordinarily long retention intervals.

The lack of spontaneous recovery in Experiment 4 might suggest that unlearning occurred after overtrained extinction. However, the most interesting aspect of that experiment's results was that, at asymptote, consumption of saccharin reached a level equivalent to control water intake, but not the saccharin intake of nonconditioned subjects. Nonconditioned subjects, unlike extinguished subjects, drank more saccharin than water. Thus, in extinction, the rats became indifferent to the saccharin flavor, but they never learned to like it. This result was also evident in Experiment 2, where saccharin consumption during the test in the extinguished groups remained below that in never-conditioned subjects, even though extinction was asymptotic, as suggested by the fact that it did not increase over test days. This effect, in addition to the spontaneous recovery evident in Experiments 1-3, is another form of evidence against the unlearning hypothesis, which would predict an equal final saccharin 
consumption independently of the previous conditioning experience.

We are not aware of any previous studies that show that extinction in taste-aversion learning reaches an asymptotic level equivalent to water consumption or indifference. In fact, previous reports using the same saccharin solution have shown an extinguished saccharin intake roughly comparable to the one displayed by nonconditioned subjects (e.g., Bouton, 1982; Schachtman et al., 1985). However, we should note that the present method might be especially sensitive to the effect. Our rats received two lengthy drinks each day ( $30 \mathrm{~min}$ each), which allowed them ample opportunity to satisfy their daily water needs. After learning the drink schedule, the rats were not compelled to drink much saccharin to satisfy the daily requirement. In contrast, previous reports allowed just one daily drink, and these were shorter than the drinks we used (20 min in Bouton, 1982; $10 \mathrm{~min}$ in Schachtman et al., 1985). With only one brief drink a day, strong thirst might have masked the difference between paired and unpaired groups that was revealed in the present experiments.

The main conclusion to be drawn from these experiments is that extinction in taste-aversion learning, as in other forms of conditioning, is not equivalent to unlearning (e.g., Bouton, 1991, 1993). The experiments reported in this paper show that spontaneous recovery after extinction of a taste aversion can be obtained (Experiments 1-3). Moreover, Experiment 4 revealed that asymptotic extinction was to a neutral preference, and never reached the preference level shown by unconditioned animals. The results of all four experiments set the grounds for understanding extinction in taste-aversion learning in the same way that it has been explained in other conditioning paradigms, for example, as the acquisition of a second "meaning" of the CS that is at least partly specific to its context and/or retention interval (e.g., Bouton, 1993).

\section{REFERENCES}

Aguado, L., Symonds, M., \& Hall, G. (1994). Interval between preexposure and test determines the magnitude of latent inhibition: Implications for an interference account. Animal Learning \& Behavior, 22, 188-194.

ARCHER, T., \& SJÖDÉN, P. O. (1981). Enviroment-dependent tasteaversion extinction: A question of stimulus novelty at conditioning. Physiological Psychology, 9, 102-108.

ArCher, T., SJödÉN, P. O., \& Nilsson, L.-G. (1985). Contextual control of taste-aversion conditioning and extinction. In P. D. Balsam \& A. Tomie (Eds.), Context and learning (pp. 225-271). Hillsdale, NJ: Erlbaum.

Archer, T., SJödÉn, P. O., Nilsson, L.-G., \& CARTer, N. (1979). Role of exteroceptive background context in taste-aversion conditioning and extinction. Animal Learning \& Behavior, 7, 17-22.

ARCher, T., SJödÉN, P. O., Nilsson, L.-G., \& CARTER, N. (1980). Exteroceptive context in taste-aversion conditioning and extinction: Odour, cage and bottle stimuli. Quarterly Journal of Experimental Psychology, 32, 197-214.

BATSELL, W. R., \& BeSt, M. R. (1992a). Investigation of replacement fluids and retention interval differences in taste-aversion learning. Bulletin of the Psychonomic Society, 30, 414-416.

BATSELL, W. R., \& BEST, M. R. (1992b). Variations in the retention of taste aversions: Evidence for retrieval competition. Animal Learning \& Behavior, 20, 146-159.

BATSELL, W. R., \& BeST, M. R. (1994). The role of US novelty in retention interval effects in single-element taste-aversion learning. Animal Learning \& Behavior, 22, 332-340.

Bouton, M. E. (1982). Lack of reinstatement of an extinguished taste aversion. Animal Learning \& Behavior, 10, 233-241.

Bouton, M. E. (1991). Context and retrieval in extinction and in other examples of interference in simple associative learning. In L. Dachowski \& C. F. Flaherty (Eds.), Current topics in animal learning: Brain, emotion, and cognition (pp. 25-53). Hillsdale, NJ: Erlbaum.

Bouton, M. E. (1993). Context, time, and memory retrieval in the interference paradigms of Pavlovian learning. Psychological Bulletin, 114, 80-99.

Bouton, M. E., \& Bolles, R. C. (1979). Contextual control of extinction of conditioned fear. Learning \& Motivation, 10, 445-466.

Bouton, M. E., \& KING, D. A. (1983). Contextual control of the extinction of conditioned fear: Test for the associative value of the context. Journal of Experimental Psychology: Animal Behavior Processes, 9, 248-265.

Bouton, M. E., \& PECK, C. A. (1989). Context effects on conditioning, extinction, and reinstatement in an appetitive conditioning preparation. Animal Learning \& Behavior, 17, 188-198.

DANGUIR, J., \& NiCOLAIDIS, S. (1977). Lack of reacquisition in learned taste aversions. Animal Learning \& Behavior, 5, 395-397.

Gisquet-VerriER, P., \& AlexinSKY, T. (1988). Time dependent fluctuations of retention performance in an aversively motivated task. Animal Learning \& Behavior, 17, 394-408.

Gustavson, K. K., Hart, J. A., Calton, J. L., \& Schactman, T. R. (1992). Effects of extinction and US reinstatement of a blocking CS-US association. Bulletin of the Psychonomic Society, 30, 247250.

Hart, J. A., Bourne, M. J., \& Schachtman, T. R. (1995). Slow reacquisition of a conditioned taste aversion. Animal Learning \& Behavior, 23, 297-303.

HowELL, D. C. (1987). Statistical methods for psychology (2nd ed.). Boston: PWS-Kent.

KAMIN, L. J. (1969). Predictability, surprise, attention, and conditioning. In B. A. Campbell \& R. M. Church (Eds.), Punishment and aversive behavior (pp. 279-296). New York: Appleton-CenturyCrofts.

Kraemer, P. J., \& Spear, N. E. (1992). The effect of nonreinforced stimulus exposure on the strength of a conditioned taste aversion as a function of retention interval: Do latent inhibition and extinction involve a shared process? Animal Learning \& Behavior, 20, 1-7.

Pavlov, I. (1927). Conditioned reflexes (G. V. Anrep, Trans.). London: Oxford University Press.

RozIN, P., \& KalAT, J. W. (1971). Specific hungers and poison avoidance as adaptive specializations of learning. Psychological Review, 78, 459-486.

Schachtman, T. R., Brown, A. M., \& Miller, R. R. (1985). Reinstatement-induced recovery of a taste- $\mathrm{LiCl}$ association following extinction. Animal Learning \& Behavior, 13, 223-227.

Schachtman, T. R., Gustavson, K. K., Chelonis, J. J., \& Bourne, M. J. (1992). Effects of US reinstatement on the potential of an extinguished CS to attenuate manifest learning about another CS. Learning \& Motivation, 23, 250-268.

SJÖDÉN, P. O., \& ARCHER, T. (1989). Taste-aversion conditioning: The role of contextual stimuli. In T. Archer \& L.-G. Nilsson (Eds.), Aversion, avoidance, and anxiety: Perspectives on aversively motivated behavior (pp. 87-120). Hillsdale, NJ: Erlbaum.

(Manuscript received August 25, 1995; revision accepted for publication October 6, 1995.) 